\title{
A Mulher Brasileira no Jornal Expresso: uma análise do discurso
}

\author{
JÉSSICA DE CASSIA RosSI \\ Universidade Sagrado Coração (USC) - jessicacrossi@yahoo.com.br \\ Professora do curso de Relações Públicas da USC, Bauru. \\ Doutoranda em Ciências Sociais pela Unesp/Marília. \\ Mestre em Comunicação pela Unesp/Bauru.
}

\begin{abstract}
Resumo
O objetivo do presente artigo é verificar como os enunciados do jornal Expresso sobre a mulher brasileira influenciam na percepção que os portugueses têm dela. Primeiramente, nos fundamentamos nas Teorias do Jornalismo e da Notícia a fim de explicar as condições a partir das quais os jornalistas produzem as notícias na contemporaneidade. Para enxergar como as notícias produzem sentidos, escolhemos usar a Análise do Discurso na linha de estudos iniciados por Pêcheux. Dessa forma, analisamos como os enunciados da notícia Fátima: Maior problema da comunidade imigrante brasileira é a imagem que the está associada - Obra Católica de Migrações publicada na versão digital do jornal Expresso, no dia 11 de agosto de 2009, influenciam a percepção que os portugueses têm sobre a mulher brasileira.
\end{abstract}

\section{Palavras-Chave}

Teorias do jornalismo e da notícia; mulher brasileira; mídia portuguesa.

\begin{abstract}
The goal of this paper is to verify how the statements of the newspaper Expresso about the Brazilian women influence the perception that the Portuguese have them. First, we have considered the theories of journalism and news in order to explain the conditions from which the journalists producing the news in nowadays. Too see how the news produces meanings, have chosen to use the Discourse Analysis in line of research started by Pêcheux. Thus, we analyze how the statements of news Fátima: maior problema da comunidade Imigrante brasileira é a imagem que lhe está associada - Obra Católica de Migrações published in the digital version of the newspaper Expresso, on August 11, 2009, influencing the perception that Portuguese have of Brazilian women.
\end{abstract}

\section{Keywords}

Theories of journalism and news; Brazilian women; Portuguese media.

Artigo recebido em 23/07/2012

Aprovado em 02/10/2012 
produção de notícias é um ato de linguagem que transmite significados
por meio de seus enunciados acerca de diversos temas. Contudo, muitas
vezes, não identificamos esses significados em uma leitura desatenta
das notícias. Para compreendê-las, precisamos utilizar um método de análise que permita ir até as Condições de Produção (CPs) de uma determinada notícia. Essa análise possibilita-nos a compreensão dos sentidos produzidos em um determinado discurso que influencia a percepção que as pessoas têm da realidade. Uma das formas que pode ser utilizada para esse entendimento é a Análise do Discurso (AD), na linha de estudos composta por autores como Pêcheux, Foucault, Maingueneau, etc. Tendo isso em vista, o objetivo do presente artigo é verificar como os enunciados do jornal Expresso sobre a mulher brasileira influenciam na percepção que os portugueses têm dela.

Para tanto, primeiramente, nos fundamentamos nas Teorias do Jornalismo e da Notícia a fim de explicar as condições a partir das quais os jornalistas produzem as notícias na contemporaneidade. Desse modo, conseguimos explicar a forma como os jornalistas enxergam a realidade e como selecionam e constroem as notícias. Para enxergar como as notícias produzem sentido, escolhemos usar a AD, na linha de estudos de Pêcheux. Ela conta com ferramentas teórico-metodológicas que investigam como o posicionamento ideológico de um sujeito em um determinado jogo de forças sociais influencia em sua produção discursiva.

Desse modo, analisamos os enunciados da notícia Fátima: Maior problema da comunidade imigrante brasileira é a imagem que lhe está associada - Obra Católica de Migrações, publicada na versão digital do jornal Expresso, no dia 11 de agosto de 2009, influenciam a percepção que os portugueses têm sobre a mulher brasileira. Analisamos como ocorre o funcionamento do discurso do jornal Expresso, o qual produz sentidos que fazem os portugueses enxergarem a mulher brasileira de uma forma e não de outra.

\section{Teorias do Jornalismo e da Notícia}

A notícia é um ato de linguagem que é produzido a partir das condições que o campo jornalístico possibilita. São diversos fatores determinados, ao longo do desenvolvimento da atividade jornalística, que fazem a notícia ser construída de uma maneira e não de outra. A especificidade dessa construção apresenta a realidade de uma 
forma própria que influencia na percepção que as pessoas têm dela. Devido a isso, apresentamos algumas reflexões das Teorias do Jornalismo e da Notícia que nos ajudam a compreender o que condiciona a produção de notícias e, dessa forma, fundamenta nossas análises no presente artigo.

$\mathrm{Na}$ contemporaneidade, o jornalismo ocidental é a forma mais praticada pelos meios de comunicação. É um tipo de jornalismo cujas raízes remontam ao surgimento de um formato jornalístico baseado na informação no século XIX e não mais na propaganda e na política. Esse formato passou a privilegiar os fatos e não mais a opinião, assim como passou a privilegiar a atualidade, a rapidez e a exclusividade. Entre as características do novo jornalismo estão: o uso de testemunhas oculares e a produção da reportagem por meio da técnica da descrição. As novas práticas do jornalismo introduziram o formato industrializado das notícias por meio do lide. As notícias passaram a ser tratadas como um produto, elas se tornaram estandartizadas ao serem produzidas no formato "pirâmide invertida". Para Traquina (2005, p.60), “[...] a utilização da pirâmide invertida reconheceu implicitamente o jornalista como 'perito' $[\ldots] "$.

Nesse contexto, também se formou o ethos do trabalho jornalístico, considerado muito importante nas sociedades democráticas. Esse ethos existente até hoje, segundo alguns profissionais da área citados por Traquina (2005), é o papel de informar a opinião pública e exercer uma função de contra-poder. Em uma democracia, o jornalismo é um meio de informação que deve conscientizar os cidadãos sobre seus direitos e expressar as preocupações sociais. Por ter esse ethos profissional, o jornalismo é regido por um conjunto de valores e normas profissionais como a liberdade, a verdade, o rigor, a exatidão, a honestidade e a objetividade. Esse último tem um sentido muito específico no campo jornalístico. Para Schudson (1978 apud TRAQUINA 2005, p.135), “[...] o conceito de objetividade no Jornalismo não surgiu como negação da subjetividade, mas como o reconhecimento de sua inevitabilidade". É uma forma que a atuação jornalística encontrou para se prevenir de qualquer ataque ou para se defender das críticas. Entre os procedimentos de defesa promovidos pelos jornalistas podemos citar, de acordo com Gaye Tuchman (1972/1993 apud TRAQUINA, 2005): a apresentação de possibilidades conflituosas, a apresentação de provas auxiliares, o uso judicioso das aspas e a estruturação da informação numa sequência apropriada. Esses procedimentos possibilitam a "objetividade jornalística", mas também é uma forma de otimizar o trabalho jornalístico. 
Esses são alguns fatores que surgiram a partir do novo jornalismo, ou seja, o jornalismo ocidental, que condicionam até hoje o processo de produção de notícias pelos jornalistas. As Teorias do Jornalismo e da Notícia apresentam diversas reflexões que procuram explicar as propriedades desse processo. São teorias que mostram como os fatores pessoais, organizacionais, profissionais e sociais influenciam o trabalho jornalístico. De modo geral, essas teorias são: a Teoria do Espelho, a Teoria da Ação Pessoal ou Teoria do Gatekeeper, a Teoria Organizacional, as Teorias de Ação Política, as Teorias Construcionistas, a Teoria Estruturalista e a Teoria Interacionista. São diversas linhas teóricas que mostram que a notícia:

[...] é o resultado da interação simultaneamente histórica e presente de forças de matriz pessoal, social (organizacional e extra-organizacional), ideológica, cultural, do meio físico e dos dispositivos tecnológicos, tendo efeitos cognitivos, afetivos e comportamentais sobre as pessoas, o que por sua vez produz efeitos de mudança ou permanência e de formação de referências sobre as sociedades, as culturas e as civilizações (SOUSA, 2000, p.9-10).

As notícias são influenciadas por uma série de fatores que concorrem entre si no processo de produção, circulação e consumo. Dentre essa série de fatores lembramos também que há um conjunto de valores pelo qual os jornalistas selecionam os acontecimentos e constroem as notícias: são os critérios de noticiabilidade ou os valores-notícia. Eles são diversos valores acordados entre a comunidade jornalística que a faz enxergar a noticiabilidade dos acontecimentos de maneira própria. É um recorte jornalístico da realidade feito pelos jornalistas que a apresenta de uma forma específica e influencia a percepção que as pessoas têm dela. Os valores-notícia, de acordo com Ponte (2005), estão ligados aos valores dominantes de uma determinada sociedade porque eles priorizam acontecimentos que reafirmam o poder social existente. Eles devem ser vistos, conforme assinala Fowler (1991 apud PONTE, 2005), não como marcas de seleção, mas sim como marcas de representação.

Por essas considerações, percebemos quais são alguns fatores que condicionam a produção de notícias. Eles nos ajudam a perceber a forma como os jornalistas enxergam a realidade que condiciona as suas produções discursivas. Além disso, nos ajudam analisar como o discurso do jornal Expresso influencia na construção de representações sobre a mulher brasileira entre os portugueses. 


\section{Análise do discurso}

A Análise do Discurso (AD), na linha de estudos de Pêcheux, é um método que vai até as Condições de Produção (CPs) de um ato de linguagem para compreender a produção de sentidos. Ela entende que as CPs de um enunciado determinam o posicionamento de um indivíduo em uma sociedade que influencia em sua produção discursiva e, dessa forma, produz determinados sentidos sobre um determinado tema. Por ter essas propriedades, escolhemos que esse método para analisar a produção de sentidos nas enunciações do jornal Expresso sobre a mulher brasileira e o modo como esses sentidos influenciam as percepções sobre elas entre os portugueses.

A AD surgiu na década de 1960, na França, a partir da confluência de três áreas do conhecimento: a Linguistica, o Marxismo e a Psicanálise. A partir delas, Pêcheux sistematizou uma nova linha de estudos discursivos; o autor mostrou que a exterioridade da linguagem influencia na construção de significados. Essa linha de estudos passou a verificar como a significação ocorre no discurso por meio de sua análise. A palavra "discurso" concentra a ideia, em sua raiz etimológica, de curso e movimento que quer dizer, de acordo com Orlandi (2003, p.15), “[...] palavra em movimento, prática de linguagem [...]". Dessa forma, o objetivo da AD é entender a linguagem produzindo sentidos em um contexto sócio-histórico.

Ao relacionar a linguagem à sua exterioridade, a $\mathrm{AD}$ nos permite identificar as regularidades discursivas dos enunciados que produzem os sentidos. De acordo com Orlandi (2003, p.16), “[...] os estudos discursivos visam pensar o sentido no tempo e no espaço das práticas do homem, descentrando a noção de sujeito e relativizando a autonomia do objeto da Linguística". A AD estabelece uma relação entre línguadiscurso-ideologia porque reconhece que a terceira depende da segunda que depende da primeira para se concretizar. É uma ligação que é realizada pelo sujeito, elo entre esses três elementos, o indivíduo é interpelado em sujeito pela ideologia e faz a língua produzir sentidos.

A partir dessas reflexões, a $\mathrm{AD}$ estabeleceu a relação da língua com o seu contexto sócio-histórico, ou seja, as CPs e por meio dos estudos de Pêcheux, segundo Brandão (1996, p.18), ela mostrou a importância dos conceitos de ideologia e discurso nos estudos da linguagem. O primeiro conceito é tributário das reflexões de Althusser sobre os "Aparelhos Ideológicos de Estado" do qual Pêcheux usou o conceito de "formação ideológica". Já o segundo conceito vem de Foucault, de sua obra 
Arqueologia do Saber, da qual Pêcheux usou a expressão "formação discursiva" para um emprego específico nos estudos do discurso.

Tendo em vista a importância dessas duas noções, Pêcheux produziu uma série de reflexões que apontam como ocorre a produção de sentidos nos enunciados e a forma como é possível analisá-los. A AD entende que o posicionamento que um sujeito ocupa em um determinado contexto social o faz enxergar a realidade de uma forma específica, que para a AD é a Formação Ideológica (FI), que influencia em sua produção discursiva, que para a $\mathrm{AD}$ representa uma Formação Discursiva (FD), a qual produz sentidos sobre determinado tema. Uma FI é a forma como a ideologia se materializa no discurso e é composta por uma ou mais Formações Discursivas (FDs) ligadas entre si. O papel delas é regular, segundo a perspectiva de uma relação de classe, o que cada posição social em uma determinada conjuntura pode e deve dizer.

Com base nessas reflexões, procuramos identificar as Formações Discursivas na notícia Fátima: Maior problema da comunidade imigrante brasileira é a imagem que lhe está associada - Obra Católica de Migrações do jornal Expresso a FI e as FDs que regulam a sua produção de sentido em relação à mulher brasileira. Para tanto, apresentamos um Quadro de Formações Discursivas com as principais FDs encontradas. Cada FD está nomeada e numerada de acordo com os seus sentidos representativos que encontramos em cada uma pelos sentidos identificados, verificamos como o jornal Expresso influencia na construção das representações da mulher brasileira entre os portugueses.

\section{Análise do discurso da notícia do jornal Expresso}

O jornal Expresso é um meio de comunicação de referência em Portugal, em conjunto com o Diário de Notícias e o jornal Público. É um jornal cuja versão impressa é publicada aos sábados e a versão digital tem atualizações diárias. A notícia Fátima: Maior Problema da comunidade imigrante brasileira é a imagem que lhe está associada - Obra Católica de Migrações, produzida pela Agência de Notícias Lusa ${ }^{i}$, foi publicada na versão digital do jornal Expresso em 11 de agosto de 2009. A matéria aborda a iniciativa da Obra Católica Portuguesa de Migrações (OCPM), da Igreja Católica, de combate ao preconceito e a discriminação que a comunidade imigrante brasileira $^{\text {ii }}$ sofre em Portugal. O jornal Expresso aponta os motivos pelos quais isso ocorre e a ação da instituição no combate a esse fenômeno. 


\section{Quadro de formações discursivas}

Formação Discursiva 1 (FD1) "Mulher Brasileira": esta FD apresenta regularidades discursivas que concebem a mulher brasileira com uma personalidade e um comportamento diferente da maioria das mulheres. Ela é vista entre os portugueses, de acordo com Pontes (2004), como uma mulher à procura de sexo, sensual e volúvel. São representações que foram construídas ao longo das relações luso-brasileiras que concebem uma imagem que desqualifica a mulher brasileira na sociedade portuguesa. No imaginário português, essas percepções estão bastante cristalizadas e mantidas principalmente pela mídia. São poucas ou quase nulas as representações que valorizam e prestigiam a mulher brasileira. Sendo assim, em muitas situações, essas regularidades discursivas retornam a cena discursiva entre os próprios portugueses e, em nosso caso, no jornal Expresso. Desse modo, identificamos na notícia Fátima: Maior Problema da comunidade imigrante brasileira é a imagem que lhe está associada - Obra Católica de Migrações os enunciados que apontam diretamente a existência dessa discriminação.

FD1 - Sentido A "O comportamento da mulher brasileira": verificamos que o jornal Expresso apresenta alguns enunciados sobre o comportamento e personalidade da mulher brasileira fundamentados nas representações negativas que apresentamos acima. Existe a percepção comum entre os portugueses de que o modo de ser da mulher brasileira é igual ou muito próximo de uma prostituta. É um estereótipo recorrente, por isso em diversas situações em que a imagem da mulher brasileira vem à tona nas produções discursivas do jornal Expresso ocorr essa associação. No caso da notícia, essa imagem surge quando se trata da presença de mulheres imigrantes brasileiras em Portugal. A presença delas no país é discriminada porque as representações sobre "o comportamento da mulher brasileira" são as primeiras percepções que os portugueses têm dela e são responsáveis por uma série de regularidades discursivas que as veem como prostitutas. Pelas enunciações do jornal Expresso, a condição de nacionalidade é um fator que cria a discriminação e o preconceito a que as mulheres imigrantes brasileiras estão associadas em Portugal. Os primeiros indícios desse reconhecimento podem ser verificados no título e no lead da notícia nos trechos a seguir: "Maior problema da comunidade imigrante brasileira é a imagem que lhe está associada - Obra Católica de Migrações”; “[...] O director da Obra 
Católica Portuguesa de Migrações (OCPM), frei Francisco Sales, disse à Agência Lusa que o maior problema da comunidade brasileira residente no país é a imagem que lhe está associada". Já os enunciados que apontam exatamente qual é a imagem que as mulheres imigrantes brasileiras estão associadas são explicados ao longo da notícia. Por eles, percebemos que o problema de imagem delas está associado à sua nacionalidade. Os enunciados que apresentam essa relação é exemplificado no trecho a seguir: “[...] 'Criaram-se estereótipos na sociedade portuguesa à volta dessa comunidade que ligam [...] à prostituição' [...]" (declaração de Francisco Sales); "No entanto, o discurso do jornal não explica os motivos pelos quais ocorre essa discriminação. Apenas aponta que a mídia teria alguma responsabilidade na (des)construção do preconceito em relação à criminalidade que os homens imigrantes brasileiros estariam associados ${ }^{\mathrm{iii}}$ e não diz nada sobre a associação das mulheres imigrantes brasileiras com a prostituição, como vemos no trecho a seguir: “[...] [Francisco Sales critica] a comunicação social [...] por 'identificar actos criminais com determinada nacionalidade' [...]'. Podemos verificar também que a maior parte dos enunciados apresentados na produção do presente sentido são feitos na voz do responsável pela iniciativa de combate à discriminação de imigrantes e não pelo jornal, o qual não explica porque ocorre esse problema. Isso ocorre porque o discurso jornalístico tende a enfatizar a situação ao invés da problemática. É um procedimento comum para a comunidade jornalística. O jornal Expresso só reconhece a discriminação de mulheres imigrantes brasileiras, de modo indireto, nas palavras de Francisco Sales. Embora o Expresso não explique a problemática da situação e só reconheça a discriminação indiretamente, apresenta enunciados sobre a iniciativa de combate a discriminação da comunidade imigrante brasileira promovido pela instituição católica portuguesa conforme vemos no trecho a seguir: "Um dos momentos mais aguardados [...] é a Perigrinação do Migrante e do Refugiado ao Santuário de Fátima [...] coincidente com a peregrinação internacional, que este ano destaca a comunidade imigrante brasileira no país”. A partir dessas considerações, acreditamos que os enunciados do jornal Expresso produzem o sentido "o comportamento da mulher brasileira".

Formação Discursiva 2 (FD2) "Próximo/Distante": esta FD está relacionada a regularidades discursivas que valorizam o que é próximo e desvaloriza o que é distante. O que está próximo é conhecido e concebido a partir de valores de uma determinada comunidade, já o que é distante e desconhecido, é visto como algo 
estranho. Por isso, as pessoas de outros países são vistas com desconfiança, porque a população local não as conhece. Em relação à receptividade de imigrantes também ocorre essa situação, nem em todos os lugares, muitas vezes, eles são bem vistos pela população autóctone. Pensam que os imigrantes podem representar algum tipo de ameaça para eles. É exatamente, dessa forma, que os portugueses se sentem em relação às mulheres imigrantes brasileiras que estão no país. Este seria outro fator que cria o preconceito que as mulheres imigrantes brasileiras sofrem em Portugal:

FD2 - Sentido A "Imigração Brasileira em Portugal”: a imigração é um fenômeno recente para os portugueses. Nas últimas décadas, o país tem recebido bastante imigrantes, entre os quais muitos brasileiros. Esse grupo não é bem visto pelos portugueses porque eles veem os imigrantes com desconfiança e como uma ameaça aos seus interesses. Em relação à mulher imigrante brasileira isso também ocorre e por isso verificamos a existência de enunciados que também a discriminam. A partir disso, o jornal Expresso aborda como a condição de imigrante dessas mulheres interfere em suas vidas em Portugal. De acordo com o jornal, a discriminação das mulheres imigrantes brasileiras é algo generalizado e por isso dificulta a vida delas no dia a dia. Entretanto, o Expresso reconhece, na voz de Francisco Sales, que essa generalização é prejudicial ao grupo e, dessa forma, justifica a importância da iniciativa da Obra Católica Portuguesa de Migrações (OCPM) de combater a discriminação, conforme verificamos no enunciado a seguir: "A maioria é gente boa. Não podemos deixar cair na generalidade uma comunidade inteira [...]" (depoimento de Francisco Sales) (LUSA, 2009, p.1). O jornal Expresso aponta também porque os imigrantes de diversas nacionalidades são discriminados em Portugal. Um dos motivos está nos problemas econômicos que o país vem passando desde o início dos anos 2000. Esses problemas acentuam a concorrência entre portugueses e imigrantes na busca pelas escassas ofertas de trabalho no país, conforme verificamos no enunciado a seguir: “[...] 'Por causa da crise econômica, o imigrante é visto como alguém que vem ocupar um posto de trabalho que poderia ser para um autóctone' exemplificou, alargando este problema à restante comunidade imigrante residente no país" (declaração de Francisco Sales). Vemos que o jornal Expresso aborda os motivos da discriminação das mulheres imigrantes brasileiras tendo em conta como a presença de alguém distante prejudica os interesses dos portugueses. Nesse ponto, o Expresso adota um posicionamento ideológico-discursivo que reconhece que a discriminação ocorre porque os imigrantes são pessoas distantes e desconhecidas 
da sociedade e da cultura lusitana. Por um lado, o Expresso admite que a sociedade portuguesa valoriza o que é próximo e discrimina o que é distante, citando, até mesmo, a existência de alguns casos de xenofobia contra imigrantes. Ele diz também que esse preconceito é algo, em geral, contra todos os imigrantes, independentemente da nacionalidade. Contudo, acreditamos que, nesse ponto, o jornal se contradiz porque, conforme nossas análises, a notícia demonstra que o preconceito contra a comunidade de imigrantes brasileiros é intenso devido "[...] à imagem que lhe está associada [...]". Se essa imagem fosse algo geral a todos os imigrantes e não particular aos brasileiros, o jornal poderia ter apresentado uma notícia que abordasse a imagem a que toda comunidade imigrante estaria associada em Portugal e não apenas uma discriminação ligada à comunidade brasileira. É por isso que acreditamos que o jornal Expresso se contradiz quando enuncia isso na voz de Francisco Sales. Os enunciados que confirmam esse posicionamento são: “[...] registam-se casos de xenofobia. 'São poucos, mas não deixam de acontecer', observou, acrescentando que 'no geral [o imigrante] não é tratado da mesma forma', independentemente da nacionalidade". Por outro lado, o Expresso enuncia, novamente na voz de Francisco Sales, que esse preconceito vem diminuindo com o decorrer dos anos, pois a sociedade portuguesa vem se acostumando com a presença dos imigrantes, como verificamos no trecho a seguir: "[...] reconhecendo que [...] a sociedade portuguesa tenha registado uma evolução positiva em matéria de integração de imigrantes [...]" (depoimento de Francisco Sales). Os enunciados apresentam características que destacam o que é importante ou não para os portugueses. O jornal Expresso noticia o combate à discriminação das mulheres imigrantes brasileira em Portugal, tentando justificar, na voz de Francisco Sales, o preconceito por parte dos portugueses com os enunciados fundamentados na presente FD. Por essa via, acreditamos que a condição de imigrante é outro fator que leva à discriminação da mulher brasileira em Portugal.

Formação Discursiva 3 (FD3) "Ordem/Desordem": esta FD separa o que está organizado do que está desorganizado. Ela apresenta regularidades discursivas que procuram enquadrar, classificar e definir todas as coisas existentes. Esses procedimentos são importantes para controlar as relações sociais, uma vez que a desordem pode representar um risco para a manutenção do status quo. Isso é feito por meio do Estado, que procura controlar todas as relações e práticas existentes a fim de imprimir ordem em um determinado lugar. Entretanto, esse controle nem sempre é integral e existem 
algumas relações e práticas que escapam da vigilância do Estado. Para tentar inibi-las, ele procura adotar formas de punições às pessoas que não cumprem as regras estatais. Esse controle do que é certo ou não pelo Estado, é denominado de legal e ilegal. Existe uma série de regularidades discursivas que surgem a partir desse posicionamento ideológico-discursivo para classificar se alguma coisa está dentro da ordem ou não, se é legal ou ilegal. Na análise da notícia em questão, verificamos também que o jornal Expresso constrói enunciados relacionados a essa classificação, quando aborda a situação das mulheres imigrantes brasileiras em Portugal:

FD3 - Sentido A "Legal/Ilegal": no que se refere ao fenômeno da imigração, um Estado procura controlar a entrada e saída de imigrantes de um determinado país. Nem todas as pessoas que vão para determinado lugar têm autorização para entrar ou permanecer nele, por isso algumas pessoas fazem isso de forma escondida para que não sejam proibidas de estarem lá. Elas precisam escapar de uma série de ações fiscalizadoras para se manter nesse país. É um sacrifício que muitos imigrantes acreditam que compensa porque, muitas vezes, os lugares para onde eles vão oferecem melhores condições de vida do que em seu país de origem. É o que acontece com uma parte das mulheres imigrantes brasileiras que vão para Portugal, de modo ilegal, em busca de melhores condições de vida. Quando o jornal Expresso aborda o fenômeno da imigração brasileira em Portugal, procura deixar claro que há uma parte desse grupo no país ilegalmente. Vejamos o trecho que aponta a condição ilegal de uma parte das mulheres imigrantes brasileiras no país no enunciado a seguir: "[...] [há a] comunidade imigrante [brasileira] no país, onde se inclui os que se encontram em situação ilegal". Por esses enunciados, acreditamos que o jornal Expresso aponta outra condição que motiva a discriminação das mulheres imigrantes brasileiras em Portugal que é a ilegalidade. Estar ilegal no país, é estar contra a ordem social portuguesa existente e ir contra os valores portugueses, por isso acreditamos que exista esse outro fator condicionante de discriminação em relação a essas mulheres. Contudo, cabe destacarmos que a prática ilegal por parte das mulheres imigrantes brasileiras em Portugal não se resume apenas à questão da imigração. Em determinado ponto da notícia, o jornal Expresso apresenta enunciados que dizem que a presença delas em Portugal está associada também à prática de atos marginais, como o tráfico de pessoas para a prostituição. Essa prática também é considerada ilegal pelo Estado português, principalmente prostitutas. Serve para confirmar a aproximação das mulheres imigrantes 
brasileiras com alguns tipos de práticas ilegais que poderiam colocar em ameaça a ordem social existente em Portugal. O enunciado que expressa isso é: “[...] apontando Portugal como um país na rota do tráfico de seres humanos para a prostituição, que está associada à mulher brasileira $[\ldots]$ ”. Pelas considerações apresentadas, acreditamos que o jornal Expresso, ao apresentar enunciados que abordam o que é legal ou não no comportamento das mulheres imigrantes brasileiras no país, produz o sentido "Legal/Ilegal" e nos apresenta mais um fator condicionante da discriminação que as mulheres imigrantes brasileiras são vítimas em Portugal, ou seja, a ilegalidade.

\section{Considerações Finais}

Pela Análise do Discurso que realizamos da notícia Fátima: Maior Problema da comunidade imigrante brasileira é a imagem que lhe está associada - Obra Católica de Migrações, pudemos identificar as FDs e os sentidos apresentados. Verificamos que há a FD1 "Mulher Brasileira" que fundamenta o sentido "O comportamento da mulher brasileira", a FD2 "Próximo/Distante" que fundamenta o sentido "Imigração Brasileira em Portugal" e a FD3 "Ordem/Desordem" que fundamenta o sentido "Legal/Ilegal". Pelo quadro de FDs analisadas, as enunciações da notícia nos apontam quais são os motivos que levam à discriminação das mulheres imigrantes brasileiras pelos portugueses. Um fator está relacionado à condição de nacionalidade dessas mulheres, o outro fator é a condição de imigrante delas em Portugal e ainda outro fator é a associação de uma parte delas à ilegalidade no país. Para a produção discursiva do jornal Expresso, ser brasileira, ou seja, ter "um comportamento diferente", ser imigrante, ou seja, ser alguém distante e estranho à cultura e sociedade portuguesa e ser ilegal, ou seja, ser alguém que não segue a ordem social portuguesa, são razões suficientes para a discriminação das mulheres imigrantes brasileiras em Portugal. É uma generalização que não dá abertura a outras possibilidades porque, embora o jornal Expresso reconheça a existência desse preconceito entre os portugueses, não apresenta outras FDs e não produz outros sentidos que descrevam a mulher brasileira de outra maneira. Por essas considerações, acreditamos que os enunciados do jornal Expresso produzem sentidos que desvalorizam a mulher brasileira entre os portugueses. 


\section{Referências}

BRANDÃO, H. N. G. Introdução à Análise do Discurso. $6^{\circ}$ ed. Campinas: Unicamp. 1997.

LUSA. Fátima: Maior problema da comunidade imigrante brasileira é a imagem que lhe está associada Obra Católica de Migrações. Jornal Expresso. Actualidade. 11 ago. 2009. Disponível em:

http://aeiou.expresso.pt/gen.pl?p=stories\&op=view\&fokey=ex.stories/530303. Acesso em: 15 maio 2010. ORLANDI, E.P. Análise de Discurso. Campinas: Pontes, 2003.

PONTE, C. Para entender as notícias - Linhas de análise do discurso jornalístico. Florianópolis: Insular. 2005.

PONTES, L. Mulheres brasileiras na mídia portuguesa. Caderno Pagu. n 23. Campinas. 2004.

Disponível em: http://www.scielo.br/scielo.php?pid=S0104-83332004000200008\&script=sci_arttext. Acesso em: 05 fev. 2010.

SOUSA, J.P. Porque as notícias são com são? Construindo uma teoria da notícia. BOCC. Universidade Fernando Pessoa. 2000. Disponível em: $<$ http://bocc.ubi.pt/pag/sousa-jorge-pedro-construindo-teoria-danoticia.pdf>. Acesso em: 15 fev. 2009.

TRAQUINA, N. Teorias do Jornalismo- Porque as notícias são como são. 2 ed. Florianópolis: Insular. 2005. (v. 1). 


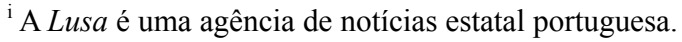

ii Apesar de a notícia tratar da discriminação da comunidade imigrante brasileira em Portugal, abordamos apenas a discriminação de mulheres imigrantes brasileiras que é o foco de nossa pesquisa.

iii Conforme enfatizamos anteriormente, a notícia trata da discriminação da comunidade de imigrantes brasileiros em geral, por isso ela apresenta também alguns enunciados que tratam da associação de homens imigrantes brasileiros à criminalidade.
\end{abstract}

Este artigo e todo o conteúdo da Estudos em Jornalismo e Mídia estão disponíveis em http://www.periodicos.ufsc.br/index.php/jornalismo/index

Estudos em Jornalismo e Mídia está sob a Licença Creative Commons. 